\title{
Phenolic Acid Content and Free Radical-Scavenging Activity of Two Differently Processed Carob Tree (Ceratonia siliqua L.) Pod
}

\author{
Hülya Torun ${ }^{1}$, Faik Ahmet Ayaz ${ }^{1 *}$, Nesrin Colak ${ }^{1}$, Jiří Grúz ${ }^{2,3}$, Miroslav Strnad ${ }^{2,3}$ \\ ${ }^{1}$ Department of Biology, Karadeniz Technical University, Trabzon, Turkey; ${ }^{2}$ Laboratory of Growth Regulators, Institute of Experi- \\ mental Botany, Palacký University, Olomouc, Czech Republic; ${ }^{3}$ Centre of the Region Haná for Biotechnological and Agricultural \\ Research, Palacký University, Olomouc, Czech Republic. \\ Email: *faa@ktu.edu.tr
}

Received July $26^{\text {th }}, 2012$; revised April $8^{\text {th }}, 2013$; accepted April $15^{\text {th }}, 2013$

Copyright (C) 2013 Hülya Torun et al. This is an open access article distributed under the Creative Commons Attribution License, which permits unrestricted use, distribution, and reproduction in any medium, provided the original work is properly cited.

\begin{abstract}
The phenolic acids in free phenolic acid (FPHA), methanol-soluble phenolic ester (MSPE), and methanol-soluble phenolic glycoside (MSPG) fractions of two carob products, natural carob-pod flour (CPF) and commercial carob-pod flour (CCPF), were identified and quantified using high-performance liquid chromatography-mass spectrometry (HPLC-MS). Six phenolic acids were identified in the carob flours (gallic acid, protocatechuic acid, gentisic acid, syringic acid, $p$ coumaric acid, and sinapic acid). Gallic acid was the major phenolic acid; and its concentrations in CCPF were substantially higher than in CPF (135 - 166 and $85.2-91.3 \mu \mathrm{g} / \mathrm{g} \mathrm{dw}$, respectively). The concentrations of $p$-coumaric acid and sinapic acid were also higher in CCPF than in CPF. In contrast, the concentrations of protocatechuic acid and gentisic acid were generally lower in CCPF than in CPF, with the only exception being gentisic acid glycosides. Both carob-pod flours contained almost the same amount of sinapic acid and syringic acid. The total phenolic contents of the FPHA, MSPE, and MSPG fractions of CPF were found to be $44 \%, 38 \%$, and $69 \%$ that of the respective fractions of CCPF. Correspondingly, the FPHA, MSPE, and MSPG fractions of CCPF had higher free radical-scavenging activity $(28.4 \%$, $33.1 \%$, and $26.2 \%$, respectively) than the corresponding fractions of CPF $(9.2 \%, 28.0 \%$, and $9.2 \%$, respectively). Notably, the FPHA and MSPG fractions of each sample had very similar scavenging activity while the MSPE fraction always had higher activity. The FPHA and MSPG fractions of CPF had the lowest activities.
\end{abstract}

Keywords: Ceratonia siliqua; Phenolic Acids; Ester; Glycoside; Carob-Pod Flour

\section{Introduction}

Oxidative stress has been identified as a factor in a number of chronic and degenerative diseases as well as in various dysfunctions. Fruits and vegetables (and recently macrofungi) have been identified as good sources of dietary antioxidants with which to combat the free radicals associated with oxidative stress. Plants are a large resource of natural antioxidants, which mainly occur as secondary metabolites and may lead to the development of novel drugs. Indeed plants are used in alternative and traditional medicine, and the increasingly larger efforts being made toward the therapy of oxidative-stress disorders has led to the development of antioxidant/free radical-scavenging studies of plants in order to benefit from their protective effects. In this respect, much effort has

*Corresponding author. been made to find more effective plant extracts and improves the scavenging activity of free radicals.

It has been reported that oxidative stress is initiated by free radicals. These highly reactive species are stabilized by electron pairing with biological macromolecules in healthy human cells, which cause damage to proteins and DNA along with lipid peroxidation. These changes contribute to cancer, atherosclerosis, cardiovascular diseases, and ageing and inflammatory diseases [1]. All human cells have the ability to protect themselves against free radical damage; by means of enzymes such as superoxide dismutase and catalase, or compounds such as ascorbic acid, tocopherol, and glutathione [1]. Sometimes these protective mechanisms are disrupted by various pathological processes, rendering antioxidant supplements vital to the combat of oxidative damage [2].

Recently, the characteristics of carob (Ceratonia sili- 
qua L.; Fabaceae) and its products have been reported in detail [3]. This tree grows in many parts of the Mediterranean region. Carob-pod, the non-fleshy, bean-like fruit of the carob tree [4], also known as locust bean, is light to dark brown and straight or slightly curved. In Turkey, carob flour may be prepared in the home from carob-pod fruit, or industrially processed carob kibble known as carob powder which may be bought from large stores and local markets [3]. This popular usage of carob leads local in- habitants/villagers to conserve existing plantations or pressure administrations to develop new planting or hybridization policies, opening new areas. Worldwide carob-pod production is increasing and has been estimated at 310,000 tonnes per year, with variable yields depending on cultivar, region, and farming practices [5]. Turkey is one of the smallest producers, with an annual production of 15,000 tonnes [3].

As a component of human diet, phenolics are non-nutrient, biologically active compounds. Phenolics occur widely in plants, mostly as polyphenols; and in fruits are frequently the most abundant secondary metabolites. At present there is much interest in phenolics from researchers and food manufacturers because of their strong antioxidant properties, their high prevalence in the human diet, and their probable role in the prevention of various diseases and of inflammation [1]. There are a number of fruits for which the phenolic content has been well-characterized. In particular, the carob-pod is wellknown for its high content of phenolics, in both the pulp and the seed. The unripe pulp is green and moist; and very astringent owing to its high phenolic content [6-8]. As the pod ripens it becomes sweet, owing to an increase in sugar content; and less astringent, owing to the polymerization and condensation of tannins $[3,6,8]$. Gallic acid, a derivative of benzoic acid, is the most abundant phenolic acid in carob-pod pulp [8-12] and also predominates in free, ester, and glycoside fractions of the harvested, unprocessed fruits.

In the present study, we investigated the phenolic content of carob-pod flour produced in Turkey, at two stages of commercial preparation: natural carob-pod flour (CPF), prepared by air drying and mechanical milling of carob-pods; and commercial carob-pod flour (CCPF), prepared by high-temperature roasting of CPF. Specifically, we evaluated the content of free and bound phenolic acids, and the antioxidant activity of these two carobpod flours.

\section{Materials and Methods}

\subsection{Sample Material}

Carob-pod flour was obtained from a commercial manufacturer with their kind permission. CPF was sampled from the production line prior to roasting; and CCPF was sampled from the final roasted product. All extractions and determinations for the two carob-pod flours were done in triplicate in parallel experiments. The results are expressed on a dry weight (dw) basis.

\subsection{Chemicals, Reagents, and Solvents}

Analytical grade standards of 3,5-dihydroxybenzoic, gallic, protocatechuic, 4-hydroxybenzoic, 3-hydroxybenzoic, gentisic, 2-coumaric, 4-coumaric, caffeic, ferulic, syringic, sinapic, chlorogenic, salicylic, trans-cinnamic, and 3coumaric acids were purchased from Sigma-Aldrich Fine Chemicals (St. Louis, MO, USA). Deuterium-labeled standards of 4-hydroxybenzoic acid $\left(2,3,5,6-\mathrm{D}_{4}\right)$ and salicylic acid $\left(3,4,5,6-\mathrm{D}_{4}\right)$ were purchased from Cambridge Isotope Laboratories (Andover, MA, USA). Formic acid and acetonitrile for HPLC were purchased from MERCK (Darmstadt, Germany) and deionized water was prepared using a Simplicity 185 deionizer (Millipore, Bedford, MA, USA).

\subsection{Extraction of Phenolic Acids from Carob-Pod}

For determination of phenolic acid composition and total phenolic content, the defatted samples were taken up in $80 \%$ methanol containing the antioxidant DBC $(2,6-$ ditercbutyl- $\beta$-cresol); for determination of antioxidant activity, DBC was omitted. The phenolic acids were fractionated according to the method of Cvikrová et al. [13], with slight modifications, to give fractions of free phenolic acids (FPHAs), methanol-soluble phenolic esters (MSPEs), and methanol-soluble phenolic glycosides (MSPGs).

\subsection{Determination of DPPH Scavenging Activity and Total Phenolic Content (TPC)}

The radical-scavenging activity of extracts and total phenolic content were determined using a modified assay for DPPH (1,1-diphenyl-2-picrylhydrazol) scavenging [14]. A $0.1 \mathrm{~mL}$ aliquot of the extract solution $(0.5-1$ $\mathrm{mg} \cdot \mathrm{mL}^{-1}$ ), $2 \mathrm{~mL}$ of $0.05 \mathrm{M}$ acetate buffer ( $\mathrm{pH} 5.5$ ), 1.9 $\mathrm{mL}$ of methanol and $1 \mathrm{~mL}$ of $0.5 \mathrm{mM}$ DPPH were mixed. The mixture was shaken immediately after adding DPPH and allowed to stand at room temperature in darkness and the decrease in absorbance at $517 \mathrm{~nm}$ was measured after 30 min until the reaction reached a plateau. These experiments were run in duplicate. The inhibitory percentage of DPPH was calculated as follows: Scavenging effect $(\%)=\left[1-(\mathrm{A}-\mathrm{Ab}) / \mathrm{A}_{0}\right] \times 100 \%$, where: $\mathrm{A}_{0}: \mathrm{A}_{517}$ of DPPH without sample (control); A: $A_{517}$ of sample and $\mathrm{DPPH}$; and $\mathrm{Ab}$ : $\mathrm{A}_{517}$ of sample without DPPH (blank).

The total phenolic content (TPC) was determined in 
fractions total, free, ester and glycoside (see Table 1) according to Moyer et al. [15]. One-hundred times diluted fruit extracts were mixed with reaction mixture containing Folin-Ciocalteu reagent, incubated at $40^{\circ} \mathrm{C}$, and the absorbance of the mixture was determined at $755 \mathrm{~nm}$ on a UV-VIS spectrophotometer (Techcomp 8500 II, South Korea). TPC was expressed as $\mathrm{mg}$ of gallic acid equivalents per $\mathrm{g}$ of fresh weight ( $\mathrm{mg}$ of $\mathrm{GAE} / \mathrm{g} \mathrm{dw}$ ).

\subsection{Determination of Phenolics by HPLC-MS}

The phenolic acid fractions were analyzed as described previously [16]. Briefly, internal standards of deuterium-labeled salicylic and $p$-hydroxybenzoic acids were added to each fraction to a final concentration of $10^{-5}$ $\mathrm{mol} / \mathrm{L}$, and $10 \mu \mathrm{L}$ of this solution was injected into a reversed-phase column (Luna Phenyl-Hexyl, $5 \mu \mathrm{m}, 250$ $\mathrm{mm} \times 2 \mathrm{~mm}$; Phenomenex, Torrance, CA). HPLC-MS analyses were performed on an Alliance 2690 Separations Module (Waters, Milford, MA, USA) linked simultaneously to a PDA 996 (Waters, Milford, MA, USA) and a ZMD 2000 single-quadrupole mass spectrometer equipped with an electrospray interface (Micromass, Manchester, UK). Data were processed by Mass Lynx software (Data Handling System for Windows, version 4.0, Micromass, Altrincham, UK). The quantification was based on the ratio of the peak area of the analyte to the average peak area of the internal standards. Deuterium-labeled internal standards of $\left[2,3,5,6-{ }^{2} \mathrm{H}_{4}\right] p$-hydroxybenzoic and $\left[3,4,5,6-{ }^{2} \mathrm{H}_{4}\right]$ salicylic acids were purchased from Cambridge Isotope Laboratories, Inc. (Andover, MA, USA). Phenolic acid composition was ex- pressed as micrograms per gram dry weight.

\section{Results}

\subsection{Phenolic Acid Compositions of Phenolic Fractions}

Analysis of free and conjugated phenolic acids in natural carob-pod flour (CPF) and commercial carob-pod flour (CCPF) by HPLC/MS revealed the presence of four hydroxybenzoic acid derivatives (HBAs; gallic, protocatechuic, gentisic, and syringic acids) and two hydroxycinnamic acid derivatives (HCAs; $p$-coumaric and sinapic acids) in the carob powder extracts. Of these, gallic acid was the most abundant, for all three fractions of both CPF and CCPF (Table 1). The concentration of gallic acid in CPF $(85.2-91.3 \mu \mathrm{g} / \mathrm{g} \mathrm{dw})$ was lower than that in CCPF $(135-166 \mu \mathrm{g} / \mathrm{g} \mathrm{dw})$. No free sinapic acid was detected in CCPF, whereas CPF contained ca. $3.2 \mu \mathrm{g} \cdot \mathrm{g}^{-1}$ $\mathrm{dw}$. The concentrations of both protocatechuic and gentisic acids in CCPF were generally higher than in CPF, with the only exception being gentisic acid glycosides. In contrast, the concentration of $p$-coumaric acid was apparently lower in CCPF than in CPF. Both carob-pod flours contained almost the same amount of sinapic and syringic acids. An apparent difference between CPF and CCPF was found in the total concentration of phenolic acids in all three fractions. The HBA to HCA ratio was always higher in CCPF than in CPF (Table 1).

Total phenolic content (TPC), determined with the Folin-Ciocalteu reagent and expressed in terms of gallic acid equivalent (GAE), followed a similar pattern to

Table 1. Phenolic acid compositions ( $\mu \mathrm{g} / \mathrm{g} \mathrm{dw})$ and total phenolic content of two preparations of carob tree (Ceratonia siliqua L.) pod. Each extraction and measurement was performed in triplicate; values shown are mean \pm standard deviation.

\begin{tabular}{ccccccc}
\hline \multirow{2}{*}{ Phenolic acid } & \multicolumn{3}{c}{ Natural carob-pod flour (CPF) } & \multicolumn{2}{c}{ Commercial carob-pod flour (CCPF) } \\
\cline { 2 - 7 } & Free & Ester & Glycoside & Free $^{\mathrm{a}}$ & Ester $^{\mathrm{b}}$ & Glycoside $^{\mathrm{c}}$ \\
\hline Gallic acid & $86.7 \pm 5.2$ & $91.3 \pm 3.5$ & $85.2 \pm 6.5$ & $166 \pm 6$ & $147 \pm 12$ & $135 \pm 17$ \\
Protocatechuic acid & $1.5 \pm 0.1$ & $2.3 \pm 0.1$ & $0.69 \pm 0.03$ & $2.8 \pm 0.1$ & $3.3 \pm 0.3$ & $1.1 \pm 0.1$ \\
Gentisic acid & $1.4 \pm 0.2$ & $0.40 \pm 0.02$ & $13.2 \pm 1.3$ & $3.1 \pm 0.1$ & $0.53 \pm 0.07$ & $7.4 \pm 0.8$ \\
Syringic acid & $0.74 \pm 0.03$ & $0.50 \pm 0.02$ & $2.3 \pm 0.1$ & $0.78 \pm 0.02$ & $0.32 \pm 0.03$ & $2.5 \pm 0.1$ \\
-Coumaric acid & $10.3 \pm 1.0$ & $16.3 \pm 1.4$ & $4.5 \pm 0.5$ & $2.6 \pm 0.2$ & $10.0 \pm 1.1$ & $2.3 \pm 0.2$ \\
Sinapic acid & $3.2 \pm 0.1$ & $7.6 \pm 0.2$ & $4.6 \pm 0.1$ & n.d. & $6.4 \pm 0.3$ & $3.2 \pm 0.1$ \\
Total HBAs ${ }^{\mathrm{d}}$ & 90.34 & 94.5 & 101.39 & 172.68 & 151.15 & 146 \\
Total HCAs & 13.5 & 23.9 & 9.1 & 2.6 & 16.4 & 5.5 \\
Total PHAs & 103.84 & 118.4 & 110.49 & 175.28 & 167.55 & 151.15 \\
TPC & $55 \pm 6.3$ & $57.0 \pm 4.3$ & $128.4 \pm 8.2$ & $123.5 \pm 10.9$ & $148.6 \pm 20.4$ & $186.0 \pm 8.9$ \\
\hline
\end{tabular}

${ }^{\mathrm{a}}$ Free phenolic acids (FPHAs) fraction; ${ }^{\mathrm{b}}$ Methanol-soluble phenolic esters (MSPEs) fraction; ${ }^{\mathrm{c}}$ Methanol-soluble phenolic glycosides (MSPGs) fraction; ${ }^{\mathrm{d}} \mathrm{HBAs}$, hydroxybenzoic acid derivatives; ${ }^{\mathrm{e}} \mathrm{HCAs}$, hydroxycinnamic acid derivatives; ${ }^{\mathrm{f}} \mathrm{PHAs}$, phenolic acids; .d. $=$ not detected. 
phenolic acid content. The TPCs of the FPHA, MSPE, and MSPG fractions of CPF were found to be $44 \%, 38 \%$, and $69 \%$ of the respective CCPF fractions (Table 1).

\subsection{Free Radical-Scavenging Activity of the Phenolic Fractions}

Primary antioxidant activity is generally measured with the 1,1-diphenyl-2-picrylhydrazyl (DPPH) assay. The DPPH assay measures the ability of an extract to donate hydrogen to the DPPH radical, which results in bleaching of the DPPH solution. The greater the bleaching action, the higher the antioxidant activity. The antioxidant activity of each of the fractions was determined in terms of the percentage of DPPH scavenged by $10 \mu \mathrm{g}$ of the dry fraction per $\mathrm{mL}$ of reaction mixture, and in terms of the $\mathrm{IC}_{50}$, the concentration of extract required to decrease by $50 \%$ the initial DPPH concentration; and these values are presented in Table 2. In terms of percentage of DPPH scavenged, the activities of the CCPF fractions $(28.4 \%$ for FPHAs, $33.1 \%$ for MSPEs, and 26.2\% for MSPGs) were higher than those of the respective CPF fractions $(9.2 \%, 28.0 \%$, and $9.2 \%)$. The $\mathrm{IC}_{50}$ values of the fractions are expressed both in terms of the concentration of carob-pod flour (in $\mathrm{mg} / \mathrm{ml}$ ) and in terms of the concentration of the fraction (in $\mu \mathrm{g} / \mathrm{ml}$ ). The $\mathrm{IC}_{50}$ values were higher for CPF than for CCPF, although they were close for the MSPE fraction. A parallel DPPH assay of gallic

Table 2. Antioxidant activity of phenolic fractions of two preparations of carob tree (Ceratonia siliqua L.) pod. Each extraction and assay was performed in triplicate; values shown are \pm standard deviation.

\begin{tabular}{cccc}
\hline & Fraction & $\begin{array}{c}\text { Natural } \\
\text { carob-pod } \\
\text { flour (CPF) }\end{array}$ & $\begin{array}{c}\text { Commercial } \\
\text { carob-pod } \\
\text { flour (CCPF) }\end{array}$ \\
\hline & Free acids $^{1}$ & $9.2 \pm 1.1$ & $28.4 \pm 1.2$ \\
$\begin{array}{c}\text { DPPH radical- } \\
\text { scavenging (\%) }\end{array}$ & Esters $^{2}$ & $28.0 \pm 1.9$ & $33.1 \pm 2.2$ \\
& Glycosides $^{3}$ & $9.2 \pm 0.6$ & $26.2 \pm 3.3$ \\
& Free acids & $23.5 \pm 2.8$ & $7.6 \pm 0.3$ \\
$\mathrm{IC}_{50}(\mathrm{mg} / \mathrm{mL})^{\mathrm{a}}$ & Esters & $7.7 \pm 0.5$ & $6.5 \pm 0.4$ \\
& Glycosides & $23.5 \pm 1.4$ & $8.3 \pm 1.0$ \\
& Free acids & $41.5 \pm 4.1$ & $6.5 \pm 0.3$ \\
$\mathrm{IC}_{50}(\mu \mathrm{g} / \mathrm{mL})^{\mathrm{b}}$ & Esters & $3.9 \pm 0.4$ & $2.9 \pm 0.5$ \\
& Glycosides & $24.0 \pm 2.4$ & $5.1 \pm 0.6$ \\
$\mathrm{IC}_{50}(\mu \mathrm{g} / \mathrm{mL})^{\mathrm{c}}$ & Gallic acid & \multicolumn{2}{c}{$1.0 \pm 0.2$} \\
\hline
\end{tabular}

${ }^{\mathrm{a}}$ Concentration of fraction expressed as concentration of carob-pod flour in the DPPH reaction mixture; ${ }^{\mathrm{b}}$ Concentration of fraction in the DPPH reaction mixture; ${ }^{\circ}$ Concentration of gallic acid standard in the DPPH reaction mixture; ${ }^{1}$ Free phenolic acid (FPHA) fraction; ${ }^{2}$ Methanol-soluble phenolic ester (MSPE) fraction; ${ }^{3}$ Methanol-soluble phenolic glycoside (MSPG) fraction. acid, the predominant compound in all the fractions, resulted in an $\mathrm{IC}_{50}$ of $1.0 \mu \mathrm{g} / \mathrm{ml}$. Notably, the FPHA and MSPG fractions exhibited the same scavenging activity. The highest activity was observed for the MSPE and MSPG fractions obtained from CCPF. This is probably due to the release of phenolic antioxidants, such as gallic acid, from the insoluble form during the roasting process, and is consistent with the high total phenolic contents of these fractions (55.0 and $57.9 \mu \mathrm{g} \mathrm{GAE} / \mathrm{g} \mathrm{dw})$. A strong positive correlation $(r=0.999)$ between DPPH activity and total phenolic content was found for $\mathrm{CPF}$, while a weaker correlation $(r=0.557)$ was found for CCPF. The present results also agree well with previous findings [17-20]. The high antioxidant contents of fruits and vegetables have been linked to the inhibition of diseases associated with oxidative damage, such as coronary heart disease, stroke, and cancers. Certain foods have even been classified as functional foods since they have been shown to promote health in such ways [21].

\section{Discussion}

Gallic acid is the most abundant phenolic acid in carobpods and their products [8-12]. This was confirmed by our present study of CPF and CCPF. One of the reasons for this high gallic acid content may be its release from tannins during the extraction process [8-12]. However, the concentrations determined in our study were lower than those reported previously for roasted carob flours, which have ranged from 264.1 to $685.6 \mu \mathrm{g} / \mathrm{g}$. These differences may be attributed to differences in carob-pod quality, source, and roasting process [10].

Many studies have investigated the effect of heat on phenolics and on antioxidant activity, and have concluded that thermal processes, including different heating methods (such as drying, microwaving, autoclaving, roasting, water immersion, pasteurization, pressuredsteam heating, and blanching), influence the degradation of phenolic compounds as well as overall antioxidant capacity [22]. Most of these thermal processes result in a degradation of phenolic compounds, although there are some exceptions. For example, it has been observed that immersion of pre-cut celery (Apium graveolens L.) in water at $50^{\circ} \mathrm{C}$ for $90 \mathrm{~s}$ resulted in a reduction in total flavonoid content of about $22 \%$ [23]; roasting of tartary buckwheat extracts at $120^{\circ} \mathrm{C}$ for $20 \mathrm{~min}$ and at $160^{\circ} \mathrm{C}$ for $30 \mathrm{~min}$ led to reductions in total flavonoid content of $12 \%$ and $16 \%$, respectively $[24,25]$; and sand roasting and microwave cooking (at $280^{\circ} \mathrm{C}$ for $20 \mathrm{~s}$ ) reduced the phenolic content of barley by $8 \%$ [26]; while an increase in temperature $\left(40^{\circ} \mathrm{C} \rightarrow 70^{\circ} \mathrm{C}\right)$ during apple-juice processing resulted in a $50 \%$ rise in flavonoid content [27]; and roasting increased the total phenolic content of 
cashew nuts and peanuts $[28,29]$.

As can be seen in Table 1, the total phenolic content and the overall concentration of phenolic acids were higher in the roasted CCPF than in the unprocessed CPF. As the CPF and CCPF were from the same batches, it can be concluded that the heating process greatly increased the concentrations of phenolic compounds. In a recent study [10] of phenolics in raw carob-pods and derived products, spectrophotometric quantification revealed an increase in the overall concentration of phenollics in the roasted carob products studied $(14.99 \mathrm{~g} / \mathrm{kg} \rightarrow$ $20.93 \mathrm{~g} / \mathrm{kg}$ ) and a slight decrease in the total content of condensed tannins $(2.24 \mathrm{~g} / \mathrm{kg} \rightarrow 2.05 \mathrm{~g} / \mathrm{kg})$; while HPLC revealed an apparent decrease in the overall concentration of phenolics as calculated from the mean concentrations of individual compounds $(4142.4 \mathrm{mg} / \mathrm{kg} \rightarrow 1207.8$ $\mathrm{mg} / \mathrm{kg}$ ), decreases in the hydrolyzable and condensed tannin concentrations $(1506.8 \mathrm{mg} / \mathrm{kg} \rightarrow 330.3 \mathrm{mg} / \mathrm{kg}$ and $191.8 \mathrm{mg} / \mathrm{kg} \rightarrow 18.7 \mathrm{mg} / \mathrm{kg}$, respectively), and a 1.8 -fold increase in the gallic acid concentration $(233.7 \mathrm{mg} / \mathrm{kg} \rightarrow$ $423.3 \mathrm{mg} / \mathrm{kg}$ ). In our study, we also found that roasting increased the gallic acid concentration and the total phenolic content. It should be mentioned that the average moisture content of the CPF before roasting was only about $8 \%$; therefore, loss of moisture from roasting cannot be the cause of the substantial increases in the gallic acid concentration, TPC, and DPPH radical-scavenging activity. Another comparison of unroasted and roasted carob powder [30] found a slight but significant increase in the tannin content of the roasted carob powder $(3.15 \%$ $\pm 0.03 \% \rightarrow 3.75 \% \pm 0.12 \%$ ).

In contrast, a clear decrease in phenolic content and antioxidant capacity following roasting was recently found for Turkish hazelnuts by Pelvan et al. [31]. They found significant losses in total phenolics (from $42.1 \%$ to $88.4 \%$ ), condensed tannins (from $30 \%$ to $95.1 \%$ ), free and bound phenolic acids (from $15.2 \%$ to $75.5 \%$ ), and oxygen-radical absorbance capacity (from $13.2 \%$ to $71.7 \%$ ). In addition, it has been reported [32] that the DPPH radical-scavenging activity of coffee beans decreased by $0.52 \%$ after light roasting (at $230^{\circ} \mathrm{C}$ for 12 min), by $2.07 \%$ after medium roasting (at $240^{\circ} \mathrm{C}$ for 14 $\mathrm{min}$ ), and by $10.26 \%$ after dark roasting (at $250^{\circ} \mathrm{C}$ for 17 min); and that dark roasting reduced the total phenolic content by $1.55 \%$. Comparison of such results should however be made with caution as the food matrices differ and may either partially protect from or facilitate degradation by heat. Degradation of phenolic compounds is an important process affecting their antioxidant activity but does not necessarily decrease it. The products of phenolic compound degradation are sometimes stronger antioxidants than the initial compounds [33,34]. Increased antioxidant capacity can also be caused by the formation of
Maillard products. Increases in antioxidant activity have been demonstrated in many studies of thermal processing $[26,28,31,32,35]$. Furthermore, synergy between antioxidants and the food matrix may occur, resulting in higher antioxidant activity than would be expected from the sample composition [36].

Such results are in agreement with our study, in which we observed increases in the antioxidant capacity and total phenolic content of carob flour after roasting. On the other hand, there are many variables in the technological process - such as milling, roasting temperature, and heating gradient- which might affect the final quality of roasted carob flour. To improve the reliability and validity of our research, we plan to investigate the effect of various temperature gradients on the antioxidant activity of carob flour in the near future.

\section{Acknowledgements}

Some of the chemicals, reagents, and instrumentation were purchased using funds awarded by the Research Fund of Karadeniz Technical University (Project Nos. 2003.111.004.5 and 2005.111.004.2) and the Scientific and Technological Research Council of Turkey (TUBITAK; TBAG Project No. 103T152). JG and MS were supported by the Academy of Sciences of the Czech Republic (KAN 200380801), the Centre of the Region Haná for Biotechnological and Agricultural Research (grant No. ED0007/01/01), and by the Czech Science Foundation (GACR P503/12/P166). The authors gratefully acknowledge this support.

\section{REFERENCES}

[1] D. Vauzour, A. Rodriguez-Mateos, G. Corona, M. J. Oruna-Concha and J. P. E. Spencer, "Polyphenols and Human Health: Prevention of Disease and Mechanisms of Action," Nutrients, Vol. 2, No. 11, 2010, pp. 1106-1131. doi:10.3390/nu2111106

[2] B. Hazra, S. Biswas and N. Mandal, "Antioxidant and Free Radical Scavenging Activity of Spondias pinnata," BMC Complementary and Alternative Medicine, Vol. 8, No. 63, 2008. doi:10.1186/1472-6882-8-63

[3] F. A. Ayaz, H. Torun, R. H. Glew, Z. D. Bak, L. T. Chuang and R. A. Presley, "Nutrient Content of CarobPod (Ceratonia siliqua L.) Flour Prepared Commercially and Domestically," Plant Foods for Human Nutrition, Vol. 64, No. 4, 2009, pp. 286-292. doi:10.1007/s11130-009-0130-3

[4] D. F. Chamberlain, “Ceratonia L.,” In: P. H. David, Ed., Flora of Turkey and the East Aegean Islands, Edinburgh University Press, Edinburgh, 1970.

[5] N. Zografakis and D. Dasenakis, "Biomass in Mediterranean Studies on the Exploitation of Carob for Bioethanol Production," Commission of the European Communities 
Directorate General for Energy and Transport, Region of Crete-Regional Energy Agency, 2002.

[6] R. Avallone, M. Plessi, M. Baraldi and A. Monzani, "Determination of Chemical Composition of Carob (Ceratonia siliqua): Protein, Fat, Carbohydrates, and Tannins," Journal of Food Composition and Analysis, Vol. 10, No. 2, 1997, pp. 166-172.

[7] A. Priolo, M. Lanza, M. Bela, P. Penisi, V. Fasone and L. Biondi, "Reducing the İmpact of Condensed Tannins in a Diet Based on Carob Pulp Using Two Levels of Polyethylene Glycol: Lamb Growth, Digestion and Meat Quality," Animal Research, Vol. 51, 2002, pp. 305-313. doi:10.1051/animres:2002026

[8] F. A. Ayaz, H. Torun, S. Ayaz, P. J. Correia, M. Alaiz, C. Sanz, J. Gruz and M. Strnad, "Determination of Chemical Composition of Anotolian Carob Pod (Ceratonia siliqua L.): Sugars, Amino and Organic Acid, Minerals and Phenolic Compounds," Journal of Food Quality, Vol. 30, No. 6, 2007, pp. 1040-1055. doi:10.1111/j.1745-4557.2007.00176.x

[9] R. W. Owen, R. Haubner, W. E. Hull, G. Erben, B. Spiegelhalder, H. Bartsch and B. Haber, "Isolation and Structure Elucidation of the Major Individual Polyphenols in Carob Fibre," Food and Chemical Toxicology, Vol. 41, No. 12, 2003, pp. 1727-1738. doi:10.1016/S0278-6915(03)00200-X

[10] M. Papagiannopoulos, H. R. Wollseifen, A. Mellenthin, B. Haber and R. Galensa, "Identification and Quantification of Polyphenols in Carob Fruits (Ceratonia siliqua L.) and Derived Products by HPLC-UV-ESI/MSn," Journal of Agricultural and Food Chemistry, Vol. 52, No. 12, 2004, pp. 3784-3791. doi:10.1021/jf030660y

[11] N. Ortega, A. Macia, M. P. Romero, E. Trullols, J. R. Morello, N. Angles and M. J. Motilva, "Rapid Determination of Phenolic Compounds and Alkoloids of Carob Flour by Improved Liquid Chromatography Tandem Mass Spectrometry," Journal of Agricultural and Food Chemistry, Vol. 57, No. 16, 2009, pp. 7239-7244. doi:10.1021/jf901635s

[12] E. M. Rakib, H. Chicha, S. Abouricha, M. Alaoui, A. A. Bouli, M. Hansali and R. W. Owen, "Determination of Phenolic Composition of Carob Pods Grown in Different Regions of Morocco," Journal of Natural Products, Vol. 3, No. 17, 2010, pp. 134-140.

[13] M. Cvikrová, M. Hrubcová, M. Vágner, I. Machácková and J. Eder, "Phenolic Acids and Peroxidase Activity in Alfalfa (Medicago sativa) Embryonic Cultures after Ethephon Treatment," Physiologia Plantarum, Vol. 91, No. 2, 1994, pp. 226-233. doi:10.1111/j.1399-3054.1994.tb00423.x

[14] M. Joyeux, M., F. Mortier and J. Fleurentin, "Screening of Antiradical, Antilipoperoxidant and Hepatoprotective Effects of 9 Plant-Extracts Used in Caribbean Folk Medicine," Phytotherapy Research, Vol. 9, No. 3, 1995, pp. 228-230. doi:10.1002/ptr.2650090316

[15] R. A. Moyer, K. E. Hummer, C. E. Finn, B. Frei, R. E. Wrolstad, "Anthocyanins, Phenolics, and Antioxidant Capacity in Diverse Small Fruits: Vaccinium, Rubus, and
Ribes," Journal of Agricultural and Food Chemistry, Vol. 50, No. 3, 2002, pp. 519-525. doi:10.1021/jf011062r

[16] F. A. Ayaz, S. Hayirlioglu-Ayaz, J. Gruz, O. Novak and M. Strnad, "Separation, Characterization, and Quantitation of Phenolic Acids in a Little-Known Blueberry (Vaccinium arctostaphylos L.) Fruit by HPLC-MS," Journal of Agricultural and Food Chemistry, Vol. 53, No. 21, 2005, pp. 8116-8122. doi:10.1021/jf058057y

[17] M. Bouaziz, M. Chamkha and S. Sayadi, "Comparative Study on Phenolic Content and Antioxidant Activity during Maturation of the Olive Cultivar Chemlali from Tunisia," Journal of Agricultural and Food Chemistry, Vol. 52, No. 17, 2004, pp. 5476-5481. doi:10.1021/jf0497004

[18] J. O. Kuti and H. B. Konuru, "Antioxidant Capacity and Phenolic Content in Leaf Extracts of Tree Spinach (Cnidoscolus spp.)," Journal of Agricultural and Food Chemistry, Vol. 52, No. 1, 2004, pp. 117-121. doi:10.1021/jf030246y

[19] T. Beta, S. Nam, J. E. Dexter and H. R. Sapirstein, "Phenolic Content and Antioxidant Activity of Pearled Wheat and Roller-Milled Fractions," Cereal Chemistry, Vol. 82, No. 4, 2005, pp. 390-393. doi:10.1094/CC-82-0390

[20] C. M. Liyana-Pathirana and F. Shahidi, "Importance of Insoluble-Bound Phenolics to Antioxidant Properties of Wheat," Journal of Agricultural and Food Chemistry, Vol. 54, No. 4, 2005, pp. 1256-1264. doi:10.1021/jf052556h

[21] R. J. Robbins, "Phenolic Acids in Foods: An Overview of Analytical Methodology," Journal of Agricultural and Food Chemistry, Vol. 51, No. 10, 2003, pp. 2866-2887. doi:10.1021/jf026182t

[22] I. Ioannou and M. Ghoul, "Biological Activities and Effects of Food Processing on Flavonoids as Phenolic Antioxidants" In: M. Petre, Ed., Advances in Applied Biotechnology, InTech, Rijeka, 2012, pp. 101-124.

[23] S. Z. Viña and A. R. Chaves, "Effect of Heat Treatment and Refrigerated Storage on Antioxidant Properties of Pre-Cut Celery (Apium graveolens L.)," International Journal of Food Science and Technology, Vol. 43, No. 1, 2008, pp. 44-51. doi:10.1111/j.1365-2621.2006.01380.x

[24] H. Zielinski, A. Mishalska, M. Amigo-Benavent, M. D. Del Castillo and M. K. Piskula, "Changes in Protein Quality and Antioxidant Properties of Buckwheat Seeds and Groats Induced by Roasting," Journal of Agricultural and Food Chemistry, Vol. 57, No. 11, 2009, pp. 47714777. doi:10.1021/jf900313e

[25] M. Zhang, H. Chen, J. Li, Y. Pei and Y. Liang, "Antioxidant Properties of Tartary Buckwheat Extracts as Affected by Different Thermal Processing Methods," LWTFood Science and Technology, Vo. 43, No. 1, 2010, pp. 181-185. doi:10.1016/j.lwt.2009.06.020

[26] P. Sharma and H. S. Gujral, "Effect of Sand Roasting and Microwave Cooking on Antioxidant Activity of Barley," Food Research International, Vol. 44, No. 1, 2011, pp. 235-240. doi:10.1016/j.foodres.2010.10.030

[27] K. A. Gerard and J. S. Roberts, "Microwave Heating of 
Apple Mash to Improve Juice Yield and Quality," LWTFood Science and Technology, Vol. 37, No. 5, 2004, pp. 551-557. doi:10.1016/j.lwt.2003.12.006

[28] N. Chandrasekara and F. Shahidi, "Effect of Roasting on Phenolic Content and Antioxidant Activities of Whole Cashew Nuts, Kernels, and Testa," Journal of Agricultural and Food Chemistry, Vol. 59, No. 9, 2011, pp. 5006-5014. doi:10.1021/jf2000772

[29] J. Yu, M. Ahmedna and I. Goktepe, "Effects of Processing Methods and Extraction Solvents on Concentration and Antioxidant Activity of Peanut Skin Phenolics," Food Chemistry, Vol. 90, No. 1-2, 2005, pp. 199-206. doi:10.1016/j.foodchem.2004.03.048

[30] A. Yousif and H. M. Alghzawi, "Processing and Characterization of Carob Powder," Food Chemistry, Vol. 69, No. 3, 2000, pp. 283-287. doi:10.1016/S0308-8146(99)00265-4

[31] E. Pelvan, C. Alasalvar and S. Uzman, "Effects of Roasting on the Antioxidant Status and Phenolic Profiles of Commercial Turkish Hazelnut Varieties (Crylus avellana L.)," Journal of Agricultural and Food Chemistry, Vol. 60, No. 5, 2012, pp. 1218-1223. doi:10.1021/jf204893x

[32] C. Somporn, A. Kamtuo, P. Theerakulpisut and S. Siriamornpun, "Effects of Roasting Degree on Radical Scavenging Activity, Phenolics and Volatile Compound of
Arabica Coffee Beans (Coffea arabica L. cv. Catimor), International Journal of Food Science and Technology, Vol. 46, No. 11, 2011, pp. 2287-2296. doi:10.1111/j.1365-2621.2011.02748.x

[33] M. Murakami, T. Yamaguchi, H. Takamura and T. Matoba, "Effects of Thermal Treatment on Radical-Scavenging Activity of Single and Mixed Polyphenolic Compounds," Journal of Food Science, Vol. 69, No. 1, 2004, pp. 7-10. doi:10.1111/j.1365-2621.2004.tb17848.x

[34] N. Buchner, A. Krumbein, S. Rhon and L. W. Kroh, "Effect of Thermal Processing on the Flavonols Rutin and Quercetin," Rapid Communications in Mass Spectrometry, Vol. 20, No. 21, 2006, pp. 3229-3235. doi: $10.1002 / \mathrm{rcm} .2720$

[35] A. Hartmann, C. D. Patz, W. Andlauer, H. Dietrich and M. Ludwig, "Influence of Processing on Quality Parameters of Strawberries," Journal of Agricultural and Food Chemistry, Vol. 56, No. 20, 2008, pp. 9484-9489. doi: $10.1021 / \mathrm{jf} 801555 \mathrm{q}$

[36] S. Wang, K. A. Meckling, M. F. Marcone, Y. Kakuda and R. Tsao, "Synergistic, Additive, and Antagonistic Effects of Food Mixtures on Total Antioxidant Capacities," Journal of Agricultural and Food Chemistry, Vol. 59, No. 3, 2011, pp. 960-968. doi:10.1021/jf1040977 